\title{
A vertigem da descontinuidade: sobre os usos da história na arqueologia de Michel Foucault
}

\section{The vertigo of discontinuity: on the use of history in Michel Foucault's archeology}

\author{
Cristiane Oliveira \\ Instituto de Medicina Social /Universidade \\ do Estado do Rio de Janeiro \\ Av. Nossa Senhora de Copacabana, 1138 \\ 22060-002 Rio de Janeiro - RJ Brasil \\ cristianeoliveira@ims.uerj.br
}

OLIVEIRA, Cristiane. A vertigem da descontinuidade: sobre os usos da história na arqueologia de Michel Foucault. História, Ciências, Saúde - Manguinhos, Rio de Janeiro, v.15, n.1, p.169-181, jan.-mar. 2008.

Abordam-se os usos da história na arqueologia de Foucault, a fim de precisar suas rupturas com o discurso da história tradicionalista. Analisa-se, inicialmente, a noção de 'arqueologia' e indicam-se os seus propósitos, tomando por base as elucidações do próprio autor. Em seguida, descreve-se a trama de noções ('acontecimento', 'formação discursiva' e 'enunciado') que se encontram enredadas no conceito de 'arquivo', buscando demonstrar a inventividade analítica desse autor para a história, problematizada a partir do paradoxo existente entre 'unidade' e 'dispersão de enunciados'. Finalmente, discute-se a enunciação de mecanismos de controle do discurso, a fim de identificar elementos de transição do trabalho descritivo das formações discursivas realizado na arqueologia do saber, para uma análise de estratégias em jogo tanto nas práticas discursivas quanto nas não-discursivas, presentes na genealogia do poder.

Palavras-chave: Foucault; arqueologia; descontinuidade; arquivo; história.

OLIVEIRA, Cristiane. The vertigo of discontinuity: on the use of history in Michel Foucault's archeology. História, Ciências, Saúde - Manguinhos, Rio de Janeiro, v.15, n.1, p.169-181, Jan.-Mar. 2008.

With the goal of identifying ruptures with traditionalist history discourse, this essay offers a reading of the various uses of history in Foucault's archeology. I begin by analyzing and describing the purpose of the notion of archeology, based on Foucault's own elucidations. I then describe the set of notions (event, discursive formation, and enunciation) intertwined within the concept of archive, in an attempt to demonstrate Foucault's analytical inventiveness in his contribution to the field of history, which he approaches from the paradox between unity and dispersion of enunciations. Lastly, I explore the enunciation of mechanisms for controlling discourse, with the aim of identifying elements of transition from descriptive work on discursive formations undertaken in the archeology of knowledge, to an analysis of the interplay of strategies both in discursive as well as non-discursive practices found in the genealogy of power.

Keywords: Foucault; archeology; discontinuity; archive; history. 
A descontinuidade é um dos eixos fundamentais na análise histórica de Michel Foucault. Essa é a estratégia utilizada no seu trabalho para desmontar os essencialismos com que enxergamos as questões de nosso tempo, para ironizar a pretensa natureza sublime da idéia de origem e para desestabilizar os lugares de verdade (e os poderes neles investidos) que ocupam os saberes, camuflados pelo discurso do conhecimento. ${ }^{1}$ Foucault acusava a história de apegarse à idéia de continuidade, subsidiada que era pela crença em uma origem essencial que subsiste ao tempo e que comanda os destinos da humanidade. Fazia eco a uma nova tradição de pensamento que combatia a noção de progresso, exaltada tanto pelos discursos filosófico e científico quanto pelo discurso capitalista, pelo efeito de verdade dado à ilusão de que o estado atual é a referência de evolução para a sociedade.

Tornar a história uma busca de continuidades é negar seu fundamento, razão pela qual podemos notar a obstinação do filósofo em especificar os usos que dela fazia, criando até mesmo designações alternativas ('arqueologia', 'genealogia') para o seu método. Com efeito, ele propõe "demorar-se nas meticulosidades e nos acasos dos começos; prestar uma atenção escrupulosa à sua derrisória maldade" (Foucault, 1995b, p.19) para que seja possível perceber as jogadas, os fluxos e os desdobramentos das batalhas sociais.

Neste artigo, pretendo realizar uma leitura dos trabalhos sobre os usos da história na arqueologia de Foucault, a fim de precisar suas rupturas com o discurso da história tradicionalista, reduto, para ele, de um desejo de continuidade presente tanto na busca de invariantes históricas quanto na preservação da categoria sujeito (Foucault, 2005a, 2000a, 2000b). Para tanto, tomarei a noção de 'descontinuidade' como eixo que atravessa toda a reflexão de Foucault sobre a história, influência das filosofias de Bachelard e Canguilhem sobre seu pensamento.

A fim de perseguir esse objetivo, sistematizo um conjunto de leituras realizadas sobre os usos da história na arqueologia foucaultiana, tomando como referências principais a $A$ arqueologia do saber, A ordem do discurso e alguns textos e entrevistas reunidos no volume II dos Ditos e escritos, intitulado "A arqueologia das ciências e dos sistemas de pensamento".

\section{A arqueologia e seus propósitos}

O uso do arkhè grego foi lapidado para significar algo muito preciso no trabalho arqueológico de Foucault: a análise de arquivos como "existência acumulada de discursos" (Foucault, 2000e, p.72). Fazendo uso de sua estratégia de desestabilizar os conceitos congelados, ele dará ao arquivo uma existência renovada. Nas suas palavras, o arquivo deve ser entendido não como um conjunto de documentos, mas sim como lei que organiza o campo do enunciável. ${ }^{2}$ Como se verá ao longo deste trabalho, um conjunto de noções se articula a esse objeto, tornando-o operatório para estabelecer, como ponto de chegada, as unidades discursivas.

'Arqueologia' é, no entanto, um termo sujeito a equívocos, uma vez que se encontra tradicionalmente enredado numa teia de sentidos que vai de encontro ao que pretendia Foucault com seu trabalho histórico, como por exemplo as idéias de origem e escavação. A arqueologia não será, pois, um estudo da origem, senão das origens relativas, das irrupções e dos começos. Grande parte de seus estudos combate a noção de 'origem', por entendê-la como recurso de uma filosofia transcendental que afirma a origem para sustentar a verdade como uma noção 
em solo firme, originário e inequívoco. Tampouco a arqueologia diz respeito aos sentidos associados à escavação, já que ele se opunha ao exercício de desvelar o sentido oculto por detrás das palavras (Foucault, 2000b).

A fim de extrair sua positividade, podemos situar a arqueologia do saber como uma analítica das condições de produção dos enunciados. Ela é apresentada, dessa forma, como uma 'reescrita' que revela como se produzem elipses, lacunas, silenciamentos, embotamentos, por um lado, e sua 'logofilia', por outro. Esse exercício torna possível a problematização da aparição fragmentada do discurso, que é aí tomado como objeto (Foucault, 2000a).

Essa designação, ainda um tanto sonâmbula, surge no projeto foucaultiano para distinguir o caráter de seu trabalho daquele da história, no sentido tradicional do termo, bem como da epistemologia. Da história, ele queria se livrar da perspectiva da continuidade e de seus efeitos políticos. Ao explicar os movimentos do devir histórico pela repetição (do mesmo), a história tradicional contribui para colocar o capitalismo numa espécie de topo da evolução de um longo processo, como destino inexorável da organização social. Foucault recusava também qualquer compromisso com a filosofia do sujeito, que, fazendo-nos crer na verdade do seu protagonismo, silenciava os efeitos de assujeitamento às tecnologias do poder.

Da epistemologia, refutava a "ilusão doxológica" de tomar por uma analítica de condições de possibilidade de uma ciência a produção de opiniões acerca do seu estatuto de cientificidade. Rejeitava também a "ilusão formalizadora", na qual se silencia a historicidade de sua produção, elidindo saber e conhecimento por meio da preocupação com os critérios formais que distinguem o campo científico dos demais. Finalmente, considerava que a "ilusão da experiência", presente na crença da espontaneidade dos objetos da ciência, permitia que a epistemologia os tomasse como realidades destituídas de efeitos discursivos (Foucault, 2000d, p.115).

A analítica dos arquivos constitui, na aurora do pensamento foucaultiano, um novo modo de interrogar a história sobre suas marcas presentes, não mais buscando a permanência, mas sim suas dispersões, limiares e descontinuidades. Para que seja possível alcançar as transformações por ele propostas na história arqueológica, é necessário reconstituir a tessitura teórica na qual ela se sustenta. Não pretendo empreender qualquer formalização de sua analítica, uma vez que ela não se deseja aprisionar em noções concebidas aprioristicamente. No entanto tentaremos acompanhar a estratégia adotada na Arqueologia do saber, com a qual se estabeleceu uma cartografia espessa e hierarquizada de conceitos e noções.

Se a arqueologia tem muito a ensinar à história e à filosofia é porque ela institui um novo modo de abordar o domínio do discurso, tomando-o como acontecimento enunciativo na sua imanência histórica. A fim de perscrutar melhor essas contribuições, torna-se necessária uma apreensão cuidadosa dessa trama conceitual, que aparece constituída, no texto de Foucault, por uma hesitação calculada perante o fechamento, a cristalização e a formalização.

\section{Extrair unidades nas dispersões: o paradoxo da construção de arquivos}

Como já vimos, o objeto da arqueologia foucaultiana é o arquivo, entendido não como conjunto de documentos que representam vestígios de verdade de outrora, mas como a lei que organiza a dispersão do discurso em conjuntos de "acontecimentos enunciativos", o que 
Foucault define como "formações discursivas" (Foucault, 2005a). Tem-se agora por tarefa redescrever essas noções amalgamadas no conceito de arquivo, o que redireciona o olhar arqueológico para uma profundidade do sentido em se concentrar na superfície das dispersões dos enunciados.

Comecemos pelo estatuto do acontecimento, que é considerado pela tradição historiográfica tradicional como um a priori, impregnado de conotação factual por meio da qual era possível extrair as causas que o explicassem. A noção de acontecimento será recolocada na arqueologia como algo da ordem da irrupção, daquilo que rompe com as regularidades de uma dada formação discursiva. Além disso, o acontecimento será pensado como multiplicidades no redobramento heterogêneo de vários acontecimentos redistribuídos em zonas distintas de visibilidade (Foucault, 2000c).

Considerar os acontecimentos em sua dispersão implica, antes de tudo, pôr em questão unidades preestabelecidas como os recortes dos campos de saber (filosofia, história e literatura, entre outros), unidades do livro, da obra e do tempo. A tarefa de suspender essas unidades aparentes se justifica, em primeira instância, por serem elas mesmas fatos discursivos, produzidos num determinado campo de referência e num momento histórico dado. Também exige recusar operadores psicológicos (presentes na noção de autoria, como intenção e consciência), razão pela qual ele traçará as devidas distinções entre enunciação e enunciado, conforme veremos mais adiante. Essas ações visam colocar em suspenso unidades já dadas, para desmontar sua aparente obviedade e percorrer seus princípios de organização, a fim de que se possa apontar a arbitrariedade da verdade que se quer afirmar.

No entanto tomar o discurso em sua dispersão não quer dizer abolir a busca de unidades, o que, na lógica dos procedimentos propostos por Foucault, significa reordenar essa massa discursiva de acordo com outros princípios revelados no trabalho de desmontagem das unidades preestabelecidas. A tarefa de descrever unidades poderia, a princípio, apresentar-se como contraditória àquela de evidenciar descontinuidades, já que poderíamos pensar que aquelas nos levariam à descrição de objetos permanentes e de continuidades, o que é impensável na lógica foucaultiana. Como conjugar, numa mesma análise, a descrição de dispersões com a exigência de que se delimite(m) a(s) unidade(s) de um determinado campo discursivo?

Após algumas pacientes páginas de idéias desistentes - nas quais ele recusa encontrar os princípios formadores de unidades em objetos existentes por si mesmos, ou na unidade temática e/ou em conceitos constitutivos de um determinado campo -, Foucault (2005a) formula a resposta a essa questão a partir do paradoxo ${ }^{3}$, por ele mesmo reconhecido como tal, que envolve a noção de formação discursiva. Tal paradoxo se manifesta na exigência de trabalho

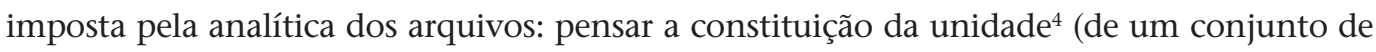
enunciados) pela definição de regras de dispersão, extraindo, com isso, sua "lei de repartição" (p.37). Uma formação discursiva conforma, dessa maneira, um conjunto de enunciados cuja unidade é produzida pela descrição das regras que presidem um "sistema de dispersão" (p.43), o qual podem ser descritas regularidades entre objetos, modalidades enunciativas, conceitos, temas/teorias (estratégias), que devemos analisar mais detidamente.

O primeiro conjunto de regras se refere à formação dos objetos de um campo discursivo. Eles seriam construídos a partir de relações entre instâncias de emergência, delimitação e especificação. Para que objetos discursivos se formem é necessário localizar múltiplas superfícies 
de emergência, com as quais será possível delimitar seus domínios. Isso implica dizer que em um campo discursivo emergem muitos objetos que serão, apenas a posteriori, selecionados. É também necessária a possibilidade de descrever as instâncias de delimitação dos objetos, a quem se delega a função de defini-los em um determinado campo discursivo. Finalmente, devemos analisar as instâncias de especificação, segundo as quais são categorizadas as diferentes expressões de um objeto. Dessas regras decorre que um objeto não é preexistente a um dado campo discursivo e que ele se forma no espaço entre o domínio discursivo e o não-discursivo, que lhe fornece as condições de possibilidade de seu aparecimento, as quais não estão, no entanto, presentes no objeto. ${ }^{5}$

Um campo discursivo também é constituído por um segundo grupo de regras de formação: o das modalidades enunciativas. Em um primeiro plano, isso requer a definição de regras que permitam acesso controlado às distintas zonas do discurso, especificando quem está autorizado a fazer ressoar os ecos de uma formação discursiva. Em seguida, implica descrever os lugares institucionais que dão suporte à existência de enunciações. Também será necessário pensar nos instrumentos (ações e modalizações) que tornam possível a construção de tipos preferenciais de enunciação.

É com a análise das modalidades enunciativas que Foucault começa a esboçar mais explicitamente a crítica à filosofia do sujeito, recorrente em sua obra (Foucault, 2005b; 2003; 2000a; 1995a; ). Essa crítica aparece direcionada inicialmente à unidade do sujeito, exposta na idéia de que há múltiplas vocalidades que entram em cena na ordem do discurso. Em acréscimo, podemos identificar o argumento de que não são os indivíduos que coordenam o quê (e como) pode ser enunciado numa formação discursiva dada, mas sim as regras que lhes preexistem. Portanto o sujeito é uma noção não só dispensável como deletéria à análise dos enunciados, porque formata a ilusão de origem presente no protagonismo daqueles que são autorizados a falar em um campo discursivo dado. Sua crítica ao sujeito associa-se a uma condenação à idéia de continuidade, pois entre essas categorias há uma espécie de solução de compromisso: "Era necessário que a história fosse contínua para que a soberania do sujeito fosse salvaguardada; mas era preciso reciprocamente que uma subjetividade constituinte e uma teleologia transcendental atravessassem a história para que ela pudesse ser pensada em sua unidade" (Foucault, 2000d, p.94).

O terceiro grupo de regras de formação diz respeito ao domínio dos conceitos. Estes são tratados como elementos discursivos, em um nível que Foucault denomina pré-conceitual. Isso quer dizer que, no trabalho arqueológico, não se trata de analisar a formalização de um sistema hierarquizado de conceitos e proposições, garantindo, com isso, uma consistência lógica ao 'edifício' teórico de uma ciência. Contrastivamente, os conceitos são tomados em um nível prévio: situados em um campo discursivo, analisamos as condições de possibilidade de emergência de um conceito, verificando como eles se dispersam. Tomemos como exemplo a sua análise sobre a doença. Em O nascimento da clínica, Foucault (2001) examina a emergência das noções de signo e probabilidade como conceitos atrelados à doença a partir do século XVIII, não porque quisesse corroborar a tese progressista dos teóricos da medicina, de que a evolução de teorias e métodos justificava a transformação do modelo classificatório para o modelo clínico, mas, ao contrário, para tomá-los como enunciados do campo discursivo da chamada medicina clínica, denunciando, no rastro da pretensão a-teórica do discurso médico 
moderno, como as relações que presidiam à formação dos conceitos instituíam o campo de possibilidades do que podia ser dito sobre a doença.

As regras de formação das estratégias são o quarto e último conjunto de regras por ele sistematizado. Ela é definida por Foucault (2005a, p.75) como um espaçamento no limite entre o domínio discursivo e o não-discursivo. Esse é um dos momentos em que os acoplamentos entre esses domínios começam a ser explorados, e talvez por isso seja uma descrição particularmente hesitante a que ele nos apresenta a esse respeito. As regras de formação das estratégias regulam os modos de utilização dos discursos, estabelecendo articulações com os outros conjuntos de regras de formação, razão pela qual elas estariam hierarquizadas em relação aos domínios dos objetos, dos conceitos e das modalidades enunciativas:

\begin{abstract}
Estas devem ser descritas como maneiras sistematicamente diferentes de tratar objetos de discurso (de delimitá-los, reagrupá-los ou separá-los, encadeá-los e fazê-los derivar uns dos outros), de dispor formas de enunciações (de escolhê-las, organizá-las, construir séries, compô-las em grandes unidades retóricas), de manipular conceitos (de lhes dar regras de utilização, fazê-los entrar em coerências regionais e constituir, assim arquiteturas conceituais) (p.77).
\end{abstract}

Após uma descrição exaustiva das regras de formação de um discurso, cujos conjuntos estabelecem entre si relações de interdependência, a assunção da tarefa de descrever novas unidades retorna à crítica inicial de Foucault feita às unidades preestabelecidas. Ele próprio se dá conta dessa armadilha em sua argumentação, ao se perguntar o que distinguiria essas unidades, forjadas no conjunto de relações estabelecidas entre objetos, temas, conceitos e estratégias de uma formação discursiva, daquelas anteriormente criticadas. A tentativa de defender essas unidades, construída com base na idéia de que elas não seriam arbitrárias, é colocada em suspensão para que outra noção seja minuciosamente analisada: o enunciado.

Ao definir uma formação discursiva como o conjunto de enunciados e o arquivo como sua regra de formação, poderíamos imaginar que o enunciado é a dimensão irredutível do discurso, ou seja, seu átomo. Mas é contra essa sugestão atomicista do enunciado que Foucault (2005a) dispara o primeiro alerta. Tudo poderia levar a crer, a princípio, na relação de elementoconjunto que o enunciado manteria com uma formação discursiva, mas esta impressão é falsa, como veremos adiante.

A segunda retificação é a de que o enunciado não se confunde com frase, nem com proposição, nem com "atos ilocutórios", pois não é demarcado pelos mesmos critérios de materialidade. Nesse sentido, os critérios gramaticais para que haja uma frase, isto é, para que ela configure uma unidade de sentido dentro de uma sintaxe lingüística, não permitem fazer equivalência desta com o enunciado, que pode prescindir dessas regras para existir. O único ponto de contato entre frase e enunciado é a dependência que o enunciado tem de signos (embora não seja redutível a eles). Também não pode equivaler a uma proposição, pois sua constituição prescinde de julgamentos lógicos de verdadeiro ou falso, análise indispensável no campo da lógica. Finalmente, enunciados não se justapõem a atos ilocutórios, já que não precisamos fazer referência a sujeitos falantes para que tenhamos enunciados. Os enunciados são, antes, condições (ou regras) de aparecimento de frases, proposições e atos ilocutórios.

Todas essas definições negativas são estratégias de desmontagem de noções já estabelecidas e de especificação de novas noções. A unidade de um enunciado será definida como da ordem 
de uma função, não de uma estrutura: "uma função que cruza um domínio de estruturas e unidades possíveis e que faz com que apareçam, com conteúdos concretos, no tempo e no espaço" (Foucault, 2005a, p.98). Como função, o enunciado não se reduz a um acoplamento de significantes e significados, assim como sua unidade não pode ser referida a uma materialidade elementarista.

A função enunciativa guarda uma relação particular com a idéia de sujeito, que não se confunde com a idéia de autor ou sujeito da enunciação. É, antes, uma função vazia, ultrapassando indivíduos que possam exercê-la. A função enunciativa dita as regras que produzem o que pode ser dito num tempo determinado, por sujeitos determinados.

A distinção entre enunciação e enunciado nos auxilia na compreensão do alcance da crítica de Foucault ao sujeito. A enunciação, como ato de vocalização de uma proposição ou frase, não se repete, pois será única a cada acontecimento. Já o enunciado pode preservar sua identidade a despeito de singularidades de enunciação, desde que obedeça a certas regras na relação com outros conjuntos de enunciados.

Mas, então, como definir a materialidade, povoada por uma relativa estabilidade, de um enunciado, já que não é nem da ordem das palavras, nem das coisas? - pergunta que continua a animar o texto de Foucault sobre a arqueologia. É o seu "campo de utilização" (Foucault, 2005a, p.118), ele nos diz, que define a materialidade do enunciado, a despeito das multivocalidades enunciativas. São as relações com outros enunciados, situadas em um campo de experiências e problemas, datados e localizados historicamente. É por isso que a análise dos enunciados busca uma "lei de raridade", busca identificar o princípio que regula o aparecimento de um enunciado, e não de outro, em condições históricas dadas.

O estatuto material de um enunciado só se define em relação com outros espaços. Não há enunciado isolado, razão pela qual Foucault (2005a) nos propõe que trabalhemos com a descrição de jogos de relações entre enunciados e grupos de enunciados, caracterizadas a partir do esquadrinhamento dos espaços entre eles: relações entre enunciados, entre grupos de enunciados e entre enunciados ou grupos de enunciados e, também, acontecimentos nãodiscursivos.

Gilles Deleuze (2005) nos oferece uma síntese bastante elucidativa do trabalho de constituição desses três tipos de espaçamentos que circundam os enunciados. O primeiro deles é o espaço colateral, constituído pelos enunciados que fazem parte de uma mesma formação discursiva, delimitada por regras de formação que a tornam reconhecível em sua unidade, o que não quer dizer homogeneidade, mas sim multiplicidade. ${ }^{6} \mathrm{O}$ espaço correlativo, por sua vez, é conformado pela relação do enunciado com seus objetos e conceitos, que, como vimos, não são dados apriorísticos. Finalmente, o espaço complementar, que é extrínseco ao campo discursivo e se constitui pela relação do enunciado com o das práticas não-discursivas: "instituições, acontecimentos políticos, práticas e processos econômicos" (Foucault, 2005a) como lugares de simultaneidade entre formação e reprodução de enunciados.

Observamos que em Foucault (2005a, 2000a) há uma insistência em negar a tradução do espaço não-discursivo como contexto, recusando, com tal gesto, qualquer tentativa de estabelecer relações de causalidade entre o discursivo e o não-discursivo. Em contrapartida, institui entre essas instâncias uma relação de imanência, tratando-as como "relações discursivas com meios não-discursivos", para usar uma síntese de Deleuze (2005, p.21), o que nos ajudaria 
a positivar o que está em jogo na relação entre esses espaços e nos livraria de pensá-los a partir das categorias de interioridade e exterioridade.

A relação entre essas instâncias (discursivo e não-discursivo) parece um dos problemas não resolvidos pela arqueologia de Foucault, apesar de sua ênfase na materialidade do discurso e na sua condição de dependência constitutiva com o domínio não-discursivo. É notável a superação da dicotomia entre discurso e prática, que atravessa os seus textos desde o primeiro tempo de seu pensamento. Mas ficamos com um olhar reticente quando se trata de apreender o que está em jogo no domínio não-discursivo, que é chamado à cena apenas na sua relação coadjuvante com o discurso, objeto do seu trabalho até então.

Após essa descrição sumarizada da trama de noções que Foucault nos apresenta, voltemos ao arquivo para averiguar se seu estatuto se transformou e, em caso positivo, em que direção. O arquivo foi definido como a lei que organiza os enunciados na sua dispersão. Mas trata-se de uma lei de raridade, o que quer dizer que o conceito de arquivo pressupõe uma organização que se faz numa temporalidade muito particular. O arquivo é a lei que institui regras de formação dos enunciados, mas também delimita suas condições de extinção. Essa pulsação arquivante, no entanto, só se torna analisável quando começa a ser alteridade, ou seja, quando as formações discursivas (e suas regras) nos causam estranheza. Desse modo, só podem ser analisadas em sua descontinuidade e pelo jogo de relações que dissolve nossa ilusão de permanência. Sem poder ser abordado pela sua atualidade, um arquivo só é analisável, portanto, pelos efeitos da passagem do tempo, que nos evidencia, no presente, a transitoriedade de sua lei e dissolve as identidades da história, fazendo-nos 'outro'.

\section{“Controlar, organizar, distribuir": nas trincheiras da ordem do discurso}

Em sua aula inaugural no Collège de France, em 1970, Foucault (2000a) sintetizou seu trabalho de esquadrinhamento da ordem do discurso situando-o em dois eixos: o crítico e o genealógico. No eixo crítico, é possível sinalizar os embotamentos, as elipses, com a suspeição tecnicamente orientada para os mecanismos de controle do discurso. Sua leitura crítica permite identificar zonas intensamente ruidosas, para que se fizesse o escrutínio de sua logofilia e de sua logofobia (termos analisados adiante). Não se tratava, porém, de identificar o significado oculto presente no ruído, mas sim de investigar que regras conduziam ao controle do discurso sobre seus objetos.

Já no segundo nível de análise, que ele nomeia como genealógico (termo que aparece sem as implicações explícitas do que ficará conhecido como um segundo corte do seu trabalho), trata-se de positivar o discurso. Um "positivismo feliz" (p.70): no seu tom irônico, evidenciando o ataque de que tinha sido vítima, o filósofo afirma que é preciso analisar o discurso em sua positividade pela "defasagem enunciativa" que lhe é constitutiva, ou seja, pela raridade que assume um determinado enunciado em condições específicas. Positivar é descobrir a lei que rege esta condição de aparecimento raro. Sua leitura genealógica se institui, portanto, a partir da possibilidade de positivar as regras de surgimento de objetos discursivos.

A ordem do discurso é produzida a partir de certos mecanismos que regulam sua organização, a fim de garantir o domínio de seus "poderes e perigos", de sua aleatoriedade e de sua materialidade: esta é a tese que o filósofo desenvolveu, naquela ocasião, no Collège de France. Esses mecanismos são categorizados a partir da sua atuação em relação à interioridade ou 
exterioridade do discurso e merecem aqui atenção, para que possamos identificar o feixe de relações que articula a organização dispersiva das formações discursivas com o seu comando ou princípio organizador, ou seja, o arquivo.

A interdição é o mecanismo mais familiar de tal controle externo exercido pela exclusão, mas esta se faz estreitando laços entre desejo e poder. Nesse sentido, Foucault (2000a) ressalta que o discurso não é um mero efeito das lutas entre dominantes e dominados, mas sim objeto de desejo, fazendo aí referência à psicanálise. O segundo princípio é a segregação, que neutraliza o perigo do discurso pela sua desqualificação, pelo apagamento de seus "efeitos de verdade", como acontece, por exemplo, com o discurso do louco, impedido de se definir como tal, ou seja, impedido de circular, de fazer laço com outros discursos. O terceiro princípio é o da "vontade de verdade", que em seu nome exclui todos aqueles que, de diferentes formas, tentaram historicamente a ela se contrapor. No século XIX aparece uma vontade de saber que se distingue da cultura clássica pelos objetos, pelas formas e pelas técnicas que utiliza. A verdade se deslocou, segundo ele, do ato ritualizado de enunciação para o enunciado. Houve uma espécie de adestramento do sujeito cognoscente para lidar com certos objetos, recortes, instrumentos, suportados institucionalmente (bibliotecas, laboratórios, pedagogia) e orientados para usos específicos do conhecimento. Esse último mecanismo, para Foucault, é o mais silenciado, embora predominante e modificador dos outros dois no nosso tempo.

O segundo grupo de procedimentos de controle do discurso são aqueles exercidos internamente, por mecanismos de classificação que visam embotar suas formações, a partir de um deslocamento do novo sentido produzido para a repetição dos sentidos já existentes. Dessa forma, a descontinuidade do comentário seria capturada pela sua adesão ao já-dito, fazendo-a existir apenas como paráfrase. Situa-se aí o paradoxo segundo o qual o comentário escancara a polissemia do texto ao mesmo tempo que, ao se vincular ao que estava oculto no texto primeiro, o destitui de seu potencial polissêmico: "a multiplicidade aberta, o acaso são transferidos, pelo princípio do comentário, daquilo que se arriscaria de ser dito, para o número, a forma, a máscara, a circunstância de repetição" (Foucault, 2000a, p.26).

Há, ainda acompanhando seu pensamento, o embotamento das descontinuidades a partir da função de autor, de difundir-se no seio da cotidianidade do falar. Foucault (2000a, p.27) define autor como "princípio de agrupamento de discurso, como unidade e origem de suas significações, como foco de sua coerência". Sinaliza uma descontinuidade na função do autor entre a idade Média (quando o autor é indicador de verdade) e a modernidade (quando o autor se enfraquece). E afirma: "o comentário limita o acaso do discurso pelo jogo de uma identidade que teria a forma de repetição e do mesmo. O princípio do autor limita este mesmo acaso pelo jogo de uma identidade que tem forma da individualidade e do eu" (p.29).

A disciplina é o terceiro mecanismo interno de dominação da ocorrência do discurso. Ela se constitui como um conjunto de regras e definições que pretendem formular proposições novas, bem como estar sob a condição de anonimato. Uma disciplina não é a soma de pressuposições verdadeiras; ela incorpora o erro como fator estratégico na produção de novas proposições. Para que uma proposição pertença a uma disciplina, além de seu valor de verdade ela precisa atender as seguintes condições: ter objeto definido e inscrever-se em certo horizonte teórico. Os limites de explicitação do discurso estão sempre condicionados ao que é fixado pelas regras já dadas, que são atualizadas permanentemente na repetição. O campo disciplinar 
reconhece o verdadeiro e o falso, repelindo suas deformidades para o exterior, onde haveria a experiência imediata, o imaginário, mas não erros. Denuncia, por fim, que a disciplina, o comentário e o autor, além de sua fecundidade discursiva, também contêm uma "função restritiva e coercitiva" (Foucault, 2000a, p.36).

Finalmente, um terceiro grupo de procedimentos é extraído do trabalho de Foucault sobre o discurso: o controle dos processos de "sujeição dos discursos" (Foucault, 2000a, p.39). Tratase de uma hierarquização do acesso às regiões do discurso, onde, por diferentes vias, se exerce numa dupla tarefa: a preservação dos segredos e a divulgação expressiva de regiões do discurso que estariam disponíveis. Tais ações conformam um mecanismo que questiona a posição discursiva de quem fala e não somente o conteúdo dos enunciados, como poderia parecer.

Com a habilidade que lhe é característica, Foucault (2000b) faz uma inversão significativa na interpretação habitual acerca da relação de nossa civilização com o discurso. Essa torção lógica desloca o nosso olhar de uma possível permissividade com os tipos de discurso, uma logofilia, para uma significativa logofobia travestida e muito bem disfarçada. Aí mesmo onde insistentemente aparece uma supervalorização do discurso, justificado pela 'vontade de verdade', pela naturalização do acontecimento e pelo apego à estrutura lingüística, situa-se o horror às suas irrupções, à sua desordem, às suas descontinuidades, aos riscos de desestabilização que invoca. Explicitemos, no entanto, desde aí, o aparecimento de sua recusa em atribuir aos mecanismos de organização dos discursos um caráter repressivo.

O trabalho de definir mecanismos de controle dos perigos do discurso, após um longo percurso para descrever suas regras de funcionamento, admite, ainda no anonimato conceitual, a necessidade de pensar as estratégias que o governam. Se na ordem do discurso uma série de procedimentos se fazem a fim de mantê-lo sob controle (o que não quer dizer repressão), cabe indagar a serviço de quê isso tudo se faz, pergunta que não é respondida nesse momento do seu trabalho, mas que consistirá uma abertura para um novo tempo de seu pensamento: a genealogia do poder. Não que o poder estivesse ausente nas suas análises anteriores, mas podemos visualizar que ele não tinha o estatuto de objeto, através das problematizações acerca das tecnologias de poder, cujos domínios são discursivos mas também não-discursivos. Nessa perspectiva, o corpo (já figurado em O nascimento da clínica) ganha relevo em suas investigações, comparecendo como instância de materialidade onde incidem essas tecnologias, lugar antes ocupado exclusivamente pelo enunciado. Espaço de sujeição ou de resistência, o corpo será tomado na sua conjunção com a história.

\section{Constelações de acontecimentos enunciativos: 0 arquivo e o caleidoscópio}

Projetando-nos nas redes de relações entre enunciados, obstinadamente descritas por Foucault ao longo de seus textos 'metodológicos' sobre a arqueologia, poderíamos metaforicamente aproximar o funcionamento de um arquivo ao de um caleidoscópio, construção imaginativa que persiste ao longo dessas leituras de Foucault. Essa máquina de ver belas imagens, tal como nos sugere sua etimologia, organiza uma disposição de multiplicidades, oferecendo-nos uma miríade de configurações possíveis. Nessa inquietante cartografia tridimensional, texturas, disposições e tonalidades são permanentemente móveis, como nos sugere a própria noção de arquivo. 
A metáfora só faz sentido se tomarmos o caleidoscópio em pleno movimento. Nesse artefato as formações discursivas poderiam ser comparadas aos conjuntos de minúsculos pedaços de vidro que se dispõem de modo contingente aos espaçamentos que se produzem com o movimento de suas peças. Nesse sentido, as partículas de vidro só formam as imagens quando se espraiam - daí a emergência das dispersões que lhe são características - pelas superfícies espelhadas que lhes servem de suporte e fornecem espaços de rarefação necessários, já que os vazios são imprescindíveis para que as figuras se formem e se transformem. As superfícies espelhadas seriam as instâncias não-discursivas, que estabelecem uma relação de imanência com as singularidades enunciativas, pois constituem as condições de possibilidade dos enunciados ao mesmo tempo que são atravessadas pelas imagens que acabaram de formar.

No entanto duas outras condições instituintes do artefato em questão são fundamentais para que essas imagens se formem: o movimento e a luz. Para conseguirmos apreciar as imagens de um caleidoscópio devemos girá-lo com força e velocidade sincronizadas, e quanto maior a destreza melhor será a forma alcançada por suas figuras. Essas exigências táticas poderiam nos servir de inspiração para pensar as lutas entre estratégias que se desenrolam no campo de forças sociais, já anunciadas na arqueologia sob a forma do jogo de forças que disputam os enunciados. Sabemos, no entanto, que somente na sua genealogia essas relações serão desenvolvidas com o vigor próprio do pensamento foucaultiano.

Ainda persiste um ponto de nossa metáfora a ser esclarecido: para que consigamos produzir alguma imagem no caleidoscópio é necessário que possamos fazer entrar luz para produzir os reflexos do jogo de espelhos. E a luz? Que lugar dar a ela neste jogo metafórico, sem que tenhamos de correr o risco de desfazer o trabalho de situar o pensamento foucaultiano fora de qualquer alusão à origem? Ou sem que tenhamos de considerá-lo um vitalista? A luz talvez pudesse ser equiparada ao que Foucault chama de "a priori histórico" ${ }^{7}$, somente através do qual podemos pensar em um campo discursivo, com sua "dispersão no tempo, um modo de sucessão, de estabilidade de reativação, uma rapidez de desencadeamento ou de rotação" (Foucault, 2005a, p.145).

\section{Ainda...}

Fazer novos usos da história requer suspensão e/ou superação de certas noções da historiografia tradicional, ancoradas na premissa da continuidade. A primeira delas é a tradição8, a qual fixa, na busca da origem, aspectos que dão uma identidade à dispersão histórica e corporificam sujeitos. A segunda noção é a de influência, que, no lastro da continuidade, propaga relações de causalidade entre as semelhanças e, ainda, serve como elemento de ligação entre unidades preestabelecidas - indivíduos, obras e teorias, por exemplo. Cabe também a problematização da idéia de desenvolvimento/evolução, que fixa um único princípio organizador, a partir do qual tudo se torna inteligível e reforça o progresso como evidência histórica. Finalmente, superar a idéia de mentalidade, que se faz criticável pelo apelo a uma noção de "consciência coletiva", que reduz a diversidade de sentidos a um "jogo de semelhança" (Foucault, 2005a, p.24).

A arqueologia de Foucault pôde significar uma nova saída para o sentimento de arbitrariedade que nos transmitem certos vetores da interpretação histórica. $\mathrm{Na}$ anarquia dos 
acontecimentos, os historiadores tradicionais pareciam fazer os documentos confessarem suas verdades ocultas, ali onde a teatralidade da história, representando o retorno de um destino dado desde sempre, ordenado, que é pura ficção, faz desaparecer a passagem do tempo e deixa o quadro sem linhas de fuga. Na arqueologia é preciso restituir aos documentos o seu caráter de monumento, rompendo com a ilusão de que eles portam uma verdade escondida para sustentá-los na sua dimensão de acontecimento.

O pensamento de Michel Foucault, marcado pela descontinuidade, faz-nos caminhar à beira: as torções propostas por sua analítica desorientam-nos num terreno onde desaparece a reconfortante idéia de permanência. Suas idéias de finitude, limite e morte são sempre conseqüentes com o caráter político a partir do qual operava: desestabilizar a permanência das interpretações que congelam na história o seu devir, não se deixando enganar pela ilusão de paz que reinaria soberana na intemporalidade dos documentos.

Acusam-no de niilista. Sem dúvida, Foucault era desprovido de qualquer otimismo ingênuo, mas suas pesquisas e seus textos atestam sempre um destino muito conseqüente ao seu pensamento: redefinir nossa participação na peça que repetem "indefinidamente os dominadores e os dominados" (Foucault, 1995b, p.24), na disputa dos enunciados, dos seus princípios de dispersão e dos seus arquivos. A vida é uma guerra! Esta é a sua premissa fundamental. Mas suas trincheiras esmaecidas fazem que oponentes se diluam em correlações de forças capilares que se instituem e se desfazem nos rastros da história: sem origem, sem sujeito, sem herói.

\section{NOTAS}

${ }^{1}$ Podemos perceber a influência de Nietzsche no pensamento de Foucault sobre a história, o que é descrito no seu artigo "Nietzsche, genealogia e a história", de 1971 (Foucault, 1995b). Reverberam aí as críticas que Nietzsche faz aos usos monumental, tradicionalista e crítico da história e no que eles podem ter de negação da vida. Ou seja, no que eles têm de busca incessante da origem e do desprezo pelo devir, no colérico artigo de juventude de Nietzsche (2005) intitulado "Sobre a utilidade e os inconvenientes da história para a vida", integrante das suas Considerações extemporâneas.

${ }^{2}$ Aqui podemos encontrar um ponto de contato entre Foucault e Derrida: o arquivo como comando, no sentido de lei de organização, tal como nos sugere a etimologia da palavra archè, é, por ambos, assinalada. Eles se encontram também na insistência em refutar as noções de essência, origem, dissolvendo as fronteiras entre interioridade e exterioridade. Parecem se distanciar, no entanto, nos seus respectivos objetivos. Para Foucault, falar em arquivo é analisar as regras de formação e de utilização uma formação discursiva dada, indicando seus propósitos, ainda na sua arqueologia, para com o poder. Derrida (1995), por sua vez, dedica-se, no tocante ao arquivo, à análise das condições espaço-temporais de produção arquivante, situados no paradoxo do "mal de arquivo". Esse paradoxo se situa no fato de que a constituição do arquivo, por depender da pulsão de morte, trabalha permanentemente contra si mesmo. Dito de outro modo, por não se deixar inscrever e ser condição para a produção do arquivo, a pulsão de morte é 'arquiviolítica', ou seja, conduz ao apagamento de todo desejo de inscrição.

${ }^{3}$ Serra (2003), na sua tese de doutorado, produz uma análise da condição paradoxal do enunciado, apresentada por Foucault em $A$ vontade de saber, estabelecendo 'relações de vizinhança' com a noção de polifonia de Mikhail Bakhtin.

${ }^{4} \mathrm{O}$ seu projeto de descrever os acontecimentos discursivos para apreender as unidades que aí se formam distingue-se tanto da análise da língua quanto da análise do pensamento. No primeiro caso, enquanto a análise da língua busca revelar as regras de construção das frases, a análise dos acontecimentos discursivos busca entender suas condições de aparição. No segundo caso, enquanto a análise do pensamento procura o sentido oculto dos signos - o que Foucault denomina "análise alegórica" -, a análise dos acontecimentos discursivos pretende explicar os lugares singulares de aparição de determinados enunciados. Nos dois 
casos trata-se de apreender as condições de produção dos enunciados, opondo claramente o projeto foucaultiano a um projeto hermenêutico ou lingüístico (Foucault, 2005a; 2000d), razão pela qual a própria definição de enunciado é modificada.

${ }^{5}$ Veremos mais adiante, a partir de uma consideração de Deleuze (2005), como esses espaços podem ser pensados em termos de organização e quais conseqüências topológicas podemos extrair disso.

${ }^{6}$ A noção de multiplicidade é analisada por Deleuze (2005) para defender que é possível pensá-la fora do antagonismo entre múltiplo (adjetivo) e Um, se nos ativermos à idéia substantivada de multiplicidades tomada como singularidades.

${ }^{7}$ Cabe ainda uma discreta advertência: esta é uma metáfora meramente geométrica; escapam-lhe quaisquer tentativas de moralizar seus efeitos estéticos.

${ }^{8}$ Alguns anos mais tarde, em 1971, Foucault fez uma análise muito eloqüente da noção de 'genealogia' e sua relação com a história em Nietzsche. Nesse ensaio, ele analisou os diversos termos utilizados por Nietzsche para referir-se à origem. Merece aqui destaque a análise do sentido de proveniência que se encontra num dos empregos de Nietzsche: uma análise da herança sinaliza não um conjunto de traços idênticos que conduzem ao produto da herança, mas sim justamente o seu oposto: falar de proveniência é falar de jogo de diferenças.

\section{REFERÊNCIAS BIBLIOGRÁFICAS}

DELEUZE, Gilles

Foucault. São Paulo: Brasiliense. 1.ed., 1986. 2005

DERRIDA, Jacques

Mal de arquivo. Rio de Janeiro: Relume-Dumará. 1.ed., 1995. 2001

FOUCAULT, Michel

A arqueologia do saber. Rio de Janeiro: Forense Universitária. 1.ed., 1967. 2005a

\section{FOUCAULT, Michel}

História da sexualidade I: a vontade de saber. Trad. e org., Roberto Machado. RJ: Graal. $1^{a}$. ed., 1976. $2005 b$

\section{FOUCAULT, Michel}

O nascimento da clínica. Rio de Janeiro: Forense Universitária. 1.ed., 1963. 2001

FOUCAULT, Michel

A ordem do discurso. São Paulo: Loyola. 1.ed., 1970. 2000a

FOUCAULT, Michel

Michel Foucault explica seu último livro: entrevista a Brochier, J.-J. In: Motta, Manoel da (Org.). Ditos e escritos II: arqueologia das ciências e história dos sistemas de pensamento. Rio de Janeiro: Forense. p. 119-126. 1.ed., 1969. 2000b

FOUCAULT, Michel

Retornar à história. In: Motta, Manoel da (Org.). Ditos e escritos II: arqueologia das ciências e história dos sistemas de pensamento. 1.ed. Rio de Janeiro: Forense. p.282-295. 1.ed., 1972. 2000c

\section{FOUCAULT, Michel}

Sobre a arqueologia das ciências: resposta ao Círculo de Epistemologia. In: Motta, Manoel da (Org.). Ditos e escritos II: arqueologia das ciências e história dos sistemas de pensamento. Rio de Janeiro: Forense. p.82-118. 1.ed., 1968. 2000d

\section{FOUCAULT, Michel}

Sobre as maneiras de escrever história: entrevista a R. Bellour. In: Motta, Manoel da (Org.). Ditos e escritos II: arqueologia das ciências e história dos sistemas de pensamento. 1.ed. Rio de Janeiro: Forense. p. 62-77. 1.ed., 1967. 2000e

FOUCAULT, Michel

Não ao sexo rei. In: Foucault, Michel. Microfísica do poder. Org. e trad. Roberto Machado. Rio de Janeiro: Graal. p.229-242. 1.ed., 1977. 1995a

\section{FOUCAULT, Michel}

Nietzsche, genealogia e história. In: Foucault, Michel. Microfísica do poder. Org. e trad. Roberto Machado. Rio de Janeiro: Graal. p.260-281. 1.ed., 1971. 1995b

\section{NIETZSCHE, Friedrich}

Consideração intempestiva II: sobre a utilidade e os inconvenientes da história para a vida. In: Niezsche, Friedrich. Escritos sobre história. Apresentação, org. e notas, Nóeli Correia de Melo Sobrinho. Rio de Janeiro: PUC/Rio; São Paulo: Loyola. p.67-178. 1.ed. do artigo, 1874. 2005

\section{SERRA, Margarida}

A multiplicidade de vozes na formação conceitual: Michel Foucault e Mikhail Bakhtin - uma relação de vizinhança. Tese (Doutorado) Universidade Federal Fluminense, Niterói. 2003 


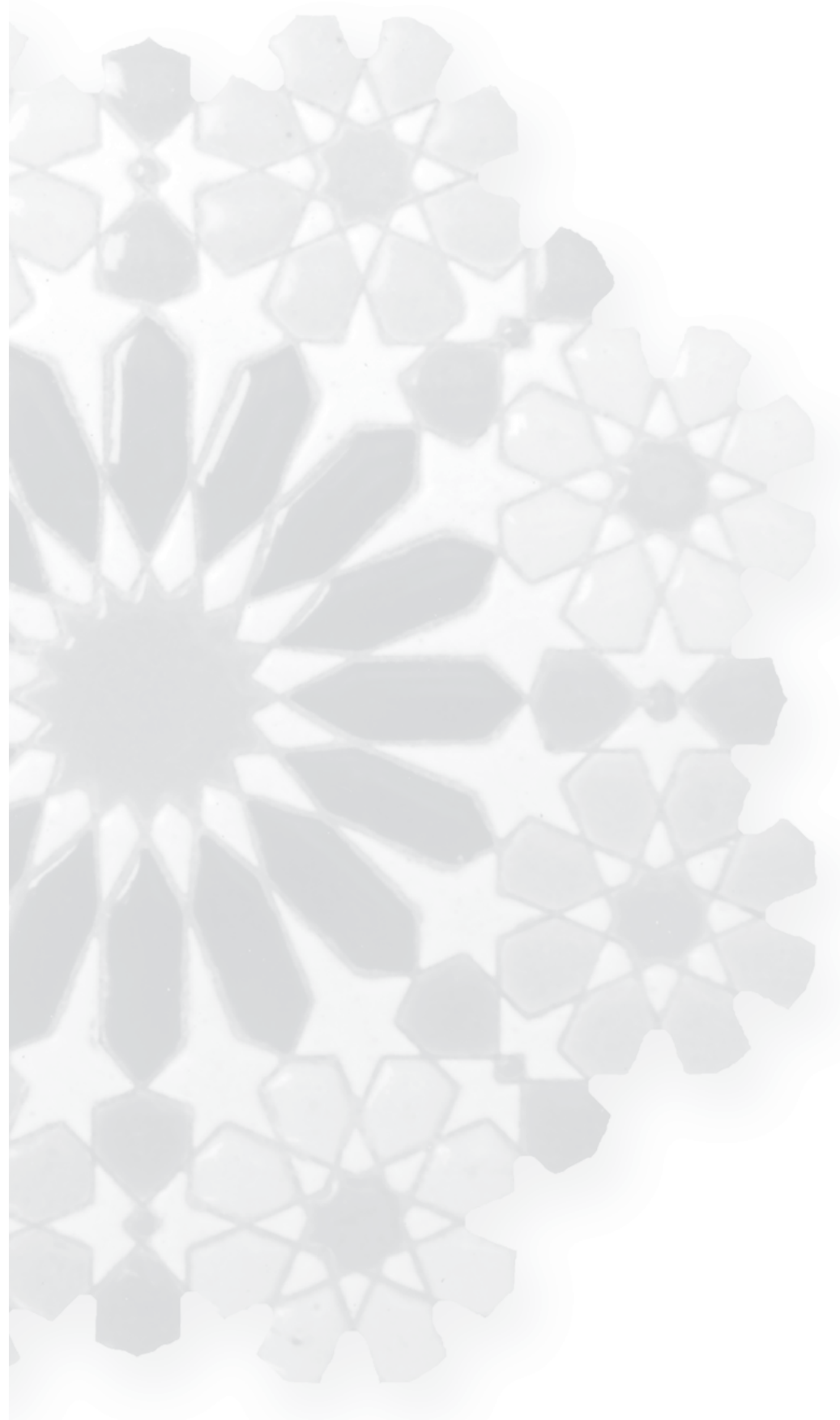

